\title{
Do large birds experience previously undetected levels of hunting pressure in the forests of Central and West Africa?
}

\author{
Robin C. Whytock, Ralph Buij, Munir Z. Virani and Bethan J. Morgan
}

\begin{abstract}
The commercial bushmeat trade threatens numerous species in the forests of West and Central Africa. Hunters shoot and trap animals, which are transported to rural and urban markets for sale. Village-based surveys of hunter offtake and surveys of bushmeat markets have shown that mammals and reptiles are affected most, followed by birds. However, hunters also consume some animals in forest camps and these may have been overlooked in surveys that have focused on bushmeat extracted from the forest. A number of studies have used indirect methods, such as hunter diaries, to quantify this additional offtake but results can be difficult to verify. We examined discarded animal remains at 13 semi-permanent hunting camps in the Ebo Forest, Cameroon, over 272 days. Twentyone species were identified from 49 carcasses, of which birds constituted $55 \%$, mammals $43 \%$ and other taxa $2 \%$. The mammals identified were typical of those recorded in previous bushmeat studies but we recorded several species of birds rarely recorded elsewhere. Offtake of bird species increased with mean body mass. We extrapolated our results to the 34 known hunting camps in the Ebo Forest and estimated that a minimum of 97 birds are hunted annually in a catchment area of c. $479 \mathrm{~km}^{2}$. We conclude that some bird species may be hunted more frequently than previous research suggests and this has important conservation implications for larger-bodied species such as raptors and hornbills.
\end{abstract}

Keywords Africa, birds, bushmeat, Cameroon, hornbills, hunting, raptors

This paper contains supplementary material that can be found online at http://journals.cambridge.org

RoBIN C. WнYTOCK (Corresponding author) Ebo Forest Research Project, c/o BP 3055, Messa, Yaoundé, Cameroon, and Department of Biological and Environmental Sciences, University of Stirling, FK9 4LA, UK

E-mail robbie@ebforest.org

RALPH BUIJ Animal Ecology Department, Alterra Wageningen UR, Wageningen, Netherlands

Munir Z. VIRANi The Peregrine Fund, Boise, Idaho, USA, and Ornithology Section, Department of Zoology, National Museums of Kenya, Nairobi, Kenya

Bethan J. Morgan Institute for Conservation Research, San Diego Zoo Global, Escondido, USA

Received 15 August 2013. Revision requested 18 October 2013. Accepted 15 January 2014. First published online 24 July 2014.

\section{Introduction}

T umans have hunted for subsistence in the forests 1 of Central and West Africa for millennia (MilnerGulland et al., 2003). However, for many people living in rural areas hunting has become an important source of revenue, driven by the high demand for bushmeat among urban populations (Fa et al., 2003; East et al., 2005). The commercial bushmeat trade has become central to many rural economies and a significant proportion of households rely on hunting as their primary source of income (Wilkie \& Carpenter, 1999). The problem has been further exacerbated by the construction of roads for commercial logging operations, which have made it easier to access previously unexploited wildlife populations and to transport meat to urban markets (Milner-Gulland et al., 2003). As a result, wildlife is subject to increasingly unsustainable hunting pressure and numerous species have been extirpated locally (Bennett et al., 2002; Fa et al., 2006).

Extensive bushmeat market and village-based surveys of hunter offtake have shown that mammals are affected most, followed by reptiles and birds ( $\mathrm{Fa}$ et al., 2006; Willcox \& Nambu, 2007; Macdonald et al., 2011). However, these surveys may fail to detect bushmeat not extracted from the forest, such as animals consumed by hunters in camps, and may underestimate total offtake (Fa \& García Yuste, 2001; Fa et al., 2006; Rist et al., 2010; Whytock \& Morgan, 2010; Allebone-Webb et al., 2011). It can be difficult to follow hunters, for logistical reasons, and many operate in secrecy because of the often illegal nature of their activities. For these reasons previous studies have used indirect methods, such as interviews with hunters, questionnaires and diaries, to quantify the number of animals discarded in the forest or consumed in hunting camps (Fa \& García Yuste, 2001; Kümpel, 2006; Willcox \& Nambu, 2007; Rist et al., 2010; Allebone-Webb et al., 2011). Although there is evidence that these methods can be effective tools for monitoring hunting activities (Jones et al., 2008; Rist et al., 2010), if participants perceive a threat to their livelihood or fear legal repercussions they may withhold information and results may be inaccurate (Jones et al., 2008). In Cameroon, for example, a number of frequently hunted species are legally protected (Fa et al., 2006; Djeukam, 2012), and the increasing enforcement of wildlife law (LAGA, 2012) means that hunters are likely to be evasive when answering questions about their activities. Thus, indirect measurements of hunter activity in the forest may be unreliable. 
In the Ebo Forest, Cameroon, previous opportunistic observations of discarded animal remains in hunting camps and informal discussions with hunters suggest that hunters kill birds such as crowned eagles Stephanoaetus coronatus (Near Threatened; IUCN, 2013) for food when working from forest camps (Whytock \& Morgan, 2010). It is therefore possible that previous bushmeat surveys underestimated offtake of these and other birds, especially where animals consumed in camps were overlooked or underreported. Hunting is considered a significant threat to many bird species in the tropical forests of Asia (Bennett et al., 1997; McConkey \& Chivers, 2004) but few studies have considered the fate of exploited bird populations in Central Africa. Crowned eagles, palm-nut vultures Gypohierax angolensis and black-casqued hornbills Ceratogymna atrata have been recorded occasionally in bushmeat surveys ( $\mathrm{Fa}$ \& García Yuste, 2001; Fa et al., 2006; Willcox \& Nambu, 2007). Although recorded in relatively low numbers these conspicuous, large-bodied birds are found at naturally low densities and are therefore particularly vulnerable to hunting pressure. Furthermore, long-lived raptors such as crowned eagles have low reproductive rates and even minimal hunting pressure can significantly perturb the balance between fecundity and longevity (Owens \& Bennett, 2000). Several birds are legally protected from hunting in Cameroon (Djeukam, 2012) and a permit must be obtained before killing or capturing crowned eagles or palm-nut vultures. It is therefore essential that offtake of these species is quantified accurately to inform future conservation action and legislative decisions (Trail, 2007; Carrete et al., 2009; Whytock \& Morgan, 2010).

To enhance our understanding of the relative effect of bushmeat hunting on birds and other animals not extracted from the forest, we examined discarded animal remains in semi-permanent hunting camps in the Ebo Forest. We quantified the number of animals discarded by hunters and predicted that large-bodied birds such as raptors and hornbills would be recorded more frequently than other taxa and that the number of bird carcasses would increase with the number of hunters using camps. Data were extrapolated to all known hunting camps in the Ebo Forest to estimate the minimum annual offtake for each species, and here we discuss the potential effect of hunting pressure on birds in the forests of West and Central Africa.

\section{Study area}

The proposed Ebo National Park (c. 1,136 km²) comprises lowland and submontane rainforest in the Littoral Region of Cameroon (Fig. 1). The forest lies within the Cross-Sanaga Region (Fa et al., 2006) and the Gulf of Guinea Biodiversity Hotspot (Oates et al., 2004) and holds important populations of several range-restricted mammals, including drills Mandrillus leucophaeus and Nigeria-Cameroon chimpanzees Pan troglodytes ellioti, as well as the Critically Endangered Ebo gorilla Gorilla gorilla and Preuss's red colobus Procolobus preussi (Morgan, 2011). The proposed National Park also forms the largest contiguous forest block within the Yabassi Important Bird Area, where several bird species on the IUCN Red List have been recorded, including crowned eagle, grey-necked rockfowl Picathartes oreas and grey parrot Psittacus erithacus (Fotso et al., 2001). For a detailed description of habitats and the anthropogenic history of the Ebo Forest see Dowsett-Lemaire \& Dowsett (2001) and Morgan (2008).

To date 34 semi-permanent hunting camps have been located in the Ebo National Park and its outliers (B. Morgan \& E. Abwe, unpubl. data). We surveyed 13 of these: four and nine belonging to hunters from Mamba and Locndeng villages, respectively (Fig. 1). These villages were selected because hunters were willing to cooperate with the study and the villages could be accessed within the logistical and financial constraints of the project. Camps were distributed throughout a large area of the forest, at varying distances from the nearest village or access roads, and because of this were assumed to be a sufficiently representative sample. Anecdotal observations suggested that hunter behaviour in the Ebo Forest (Supplementary Material 1) is similar to that described elsewhere in Central Africa (Fa \& García Yuste, 2001; Willcox \& Nambu, 2007; Rist et al., 2010) and that results are likely to be representative of the wider region.

\section{Methods}

\section{Hunting camp surveys}

During 1 July 2011-28 March 2012 camps were searched for animal remains discarded by hunters. These dates were chosen to cover both the wet and dry seasons (sensu Fa et al., 2004, 2006), as hunting effort and species availability may vary seasonally. The survey period covered 272 days, with 94-265 survey days per camp (mean $196 \pm$ SE 22 days). Meetings with local chiefs were held to explain the purpose of the study and seek permission to access camps before commencing fieldwork. Hunters in each village were employed as field assistants and porters, for a small fee. We used a global positioning system (GPS) to relocate camps and map established trails. Each camp was surveyed approximately once every 8 weeks, during daylight hours. This time-frame was considered short enough to ensure that remains such as bones and feathers were recorded before they decomposed beyond recognition, although some may have been removed by scavengers.

Surveys involved walking slowly within a $25 \mathrm{~m}$ radius of the camp, scanning the ground for animal remains. Searches were limited to $25 \mathrm{~m}$ because it was deemed unlikely that hunters would throw discarded remains beyond this distance in dense forest. Areas used regularly by hunters to 


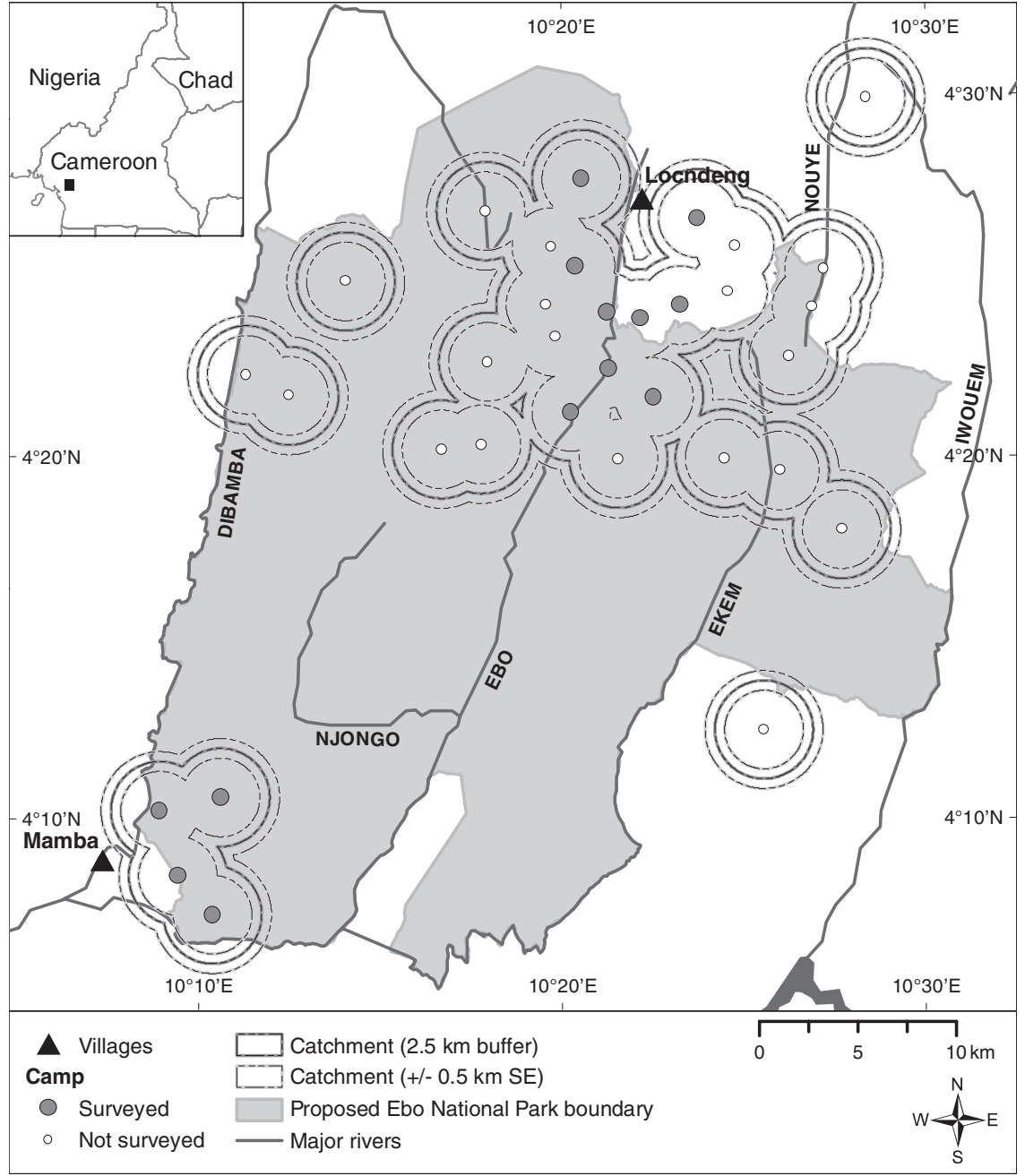

FIG. 1 The locations of 34 hunting camps in the vicinity of the proposed Ebo National Park, Cameroon, with an estimated total catchment area of 479 $\mathrm{km}^{2}$, based on a $2.5 \mathrm{~km}$ radius buffer around each camp. The 13 camps surveyed are indicated by grey filled circles. The rectangle on the inset indicates the location of the main map in Cameroon. prepare carcasses were also searched opportunistically. Opportunistic, informal interviews with hunters were used to estimate the number of hunters using camps between surveys. Animal parts were photographed alongside a unique data sheet showing the date, name of camp, name of nearest village, approximate number of hunters using the camp since the last survey, GPS location and an identification number. Once photographed, remains were destroyed or discarded far from camp to prevent repeat counts.

Remains were identified from photographs, using Borrow \& Demey (2004) for birds, Kingdon (1997) for mammals and Chirio \& LeBreton (2007) for reptiles. Crania, limb bones, and tail and primary feathers were counted to estimate the total number of individuals. Remains were identified to species level where possible. We use the term carcass to indicate that at least part of one individual was identified.

\section{Data analysis}

To estimate total harvest during the study period, results from the first visit to each camp were excluded from the analysis because of the presence of accumulated remains from an unknown time period. We used Spearman's rank correlation $\left(r_{s}\right)$ to test for a relationship between the number of hunters using camps and the number of bird carcasses recorded. We also used $r_{s}$ to test for a relationship between the approximate adult body mass of birds identified to genus or species level and the number of carcasses identified. Adult body mass estimates were taken from Urban et al. (1982), Fry et al. (1988) and Ferguson-Lees \& Christie (2001). Statistical analyses were carried out in Minitab v. 16 (Minitab, State College, USA) at a significance level of 0.05 .

To estimate the minimum annual offtake for the study area we extrapolated mean totals for each species to the 34 known hunting camps in the Ebo Forest and then extrapolated the data to an entire year. Results were rounded to whole numbers. We estimated the catchment area of the 34 camps to compare our results with bushmeat data from previous urban market and village-based hunter surveys in the same region (Fa et al., 2006; Willcox \& Nambu, 2007). To do this we estimated the mean area exploited by an individual camp and extrapolated to all known camps. We assumed that camps were spatially distributed so that 
hunters could (1) exploit new areas of the forest, and (2) work simultaneously in neighbouring camps without significant interference. Camps were linked by well-maintained, established trails and these were mapped using a handheld GPS. We used these data to calculate the mean walking distance between adjacent camps and this was used as a proxy for the mean catchment diameter. Using ArcMap v. 10.0 (ESRI, Redlands, USA) we extrapolated results to all 34 camps and calculated their combined catchment area (Fig. 1).

\section{Results}

During 50 survey events we recorded 49 carcasses (mean $0.98 \pm$ SE 0.11 per survey) comprising 21 species (Table 1 ). The mean number of carcasses recorded per camp was $3.77 \pm$ SE 0.72 (range $0-8$ ) and 2-7 surveys were carried out in each camp (mean $3.85 \pm$ SE 0.39). The majority of carcasses were birds (55\%) and mammals (43\%). The most frequently recorded birds were hornbills $(37 \%)$ and raptors $(33 \%)$. Rodents, duikers and guenons were the most frequently recorded mammals, accounting for $19 \%$ of carcasses. The mean number of hunters using camps between surveys was $2.11 \pm \mathrm{SE} 0.31$ (range $0-7$ ) and the number was correlated positively with the total number of bird carcasses recorded $\left(r_{s}=0.70, \mathrm{P}<0.001, \mathrm{n}=50\right.$ surveys $)$. There was also a positive correlation between the number of carcasses recorded and the approximate adult body mass of bird species $\left(r_{s}=0.73, \mathrm{P}=0.027, \mathrm{n}=25\right.$ carcasses), suggesting that larger species were killed more often than smaller species. It was not possible to identify the age of most individuals from remains, with the exception of one adult and three subadult palm-nut vultures, two juvenile African goshawks Accipiter tachiro and an adult African harrierhawk Polyboroides typus. We were unable to identify the sex of any individuals.

The mean walking distance between 10 adjacent camps was $5 \pm \mathrm{SE} 0.5 \mathrm{~km}$ and the combined catchment area for all 34 camps was estimated to be $479 \mathrm{~km}^{2}$ (range $353-598 \mathrm{~km}^{2}$, using SE of mean walking distance; Fig. 1). Estimates of total bird offtake based on previous market and village-based studies carried out in the Cross-Sanaga region were similar when corrected for catchment area size but a much higher mammal offtake was estimated based on those studies (Table 1). Species composition differed between assessments, with a greater diversity of birds recorded in hunting camps compared to market and village-based surveys.

\section{Discussion}

Our results indicate that some large-bodied bird species are experiencing previously unrecognized levels of mortality from bushmeat hunting, which to the best of our knowledge has not been observed elsewhere in West and Central Africa.
Our results are likely to be underestimates because some remains may have been permanently disposed of by hunters (such as on the campfire), removed by scavengers or decomposed between survey events. However, we observed a positive relationship between the number of hunters using camps and the number of bird carcasses recorded, which suggests that the proportion of bird carcasses overlooked during surveys and the effects of disposal by hunters, removal by scavengers or decomposition remained relatively constant. We conclude that some birds, particularly raptors and hornbills, are hunted more often than previous research suggests and this has important conservation implications for a number of species.

Our estimate of the total number of birds killed annually in the catchment area is similar to estimates based on market and village-based hunter surveys but species composition and estimates for individual species vary. However, extrapolated estimates of annual offtake per unit area should be interpreted with caution because catchment areas were estimated crudely in this study and those presented for comparison. In Sendje, Equatorial Guinea, the maximum daily distances travelled by hunters operating from camps was estimated to be $3.2 \mathrm{~km}$ (see Table 1 in Abernethy et al., 2013), which is c. $20 \%$ further than our estimated catchment radius of $2.5 \mathrm{~km}$. However, hunters in Sendje were almost exclusively trappers (Kümpel, 2006) whereas gun-hunting is thought to be more common than trapping in the Ebo Forest. Gun-hunters probably operate over shorter distances, covering a wider area, and based on the geographical distribution and density of the known hunting camps in the Ebo Forest (Fig. 1) our catchment estimate seems reasonable.

The most frequently recorded bird in this study, the white-thighed hornbill Bycanistes albotibialis, was not recorded in either of the studies presented for comparison, which recorded a combined total of nearly 250,000 carcasses and are the most extensive surveys of bushmeat carried out in the Cross-Sanaga region to date (Fa et al., 2006; Willcox \& Nambu, 2007). Offtake of the second-most frequently recorded bird, the palm-nut vulture, was also significantly underestimated by market and village-based hunter surveys. Additionally, although recorded in relatively low numbers, raptors formed a significant proportion of bird carcasses in our surveys but were recorded only rarely in other studies. Both of the studies used for comparison estimated higher levels of offtake for the black-casqued hornbill and crested guineafowl Guttera pucherani and also identified two additional bird species that were not detected in our study but which are known from the Ebo Forest: African grey parrot Psittacus erithacus (Vulnerable; IUCN, 2013) and pied kingfisher Ceryle rudis (Fa et al., 2006; Willcox \& Nambu, 2007). There may be a number of reasons for these disparities, for example geographical or cultural differences between the three study areas may explain the variation in 
TABLE 1 The total and mean number of carcasses recorded in 13 hunting camps in and around the proposed Ebo National Park in Cameroon (Fig. 1) over 272 days during 2011-2012. Mean values were extrapolated to estimate annual offtake in all known hunting camps in the Ebo Forest and its outliers, with an estimated catchment of $479 \mathrm{~km}^{2}$. For comparison, we present annual estimates from two previous market and village-based studies carried out in the Cross-Sanaga region, adjusted for catchment size (Fa et al., 2006; Willcox \& Nambu, 2007). Mean adult body mass estimates are presented where possible (Urban et al., 1982; Fry et al., 1988; Kingdon, 1997; Ferguson-Lees \& Christie, 2001).

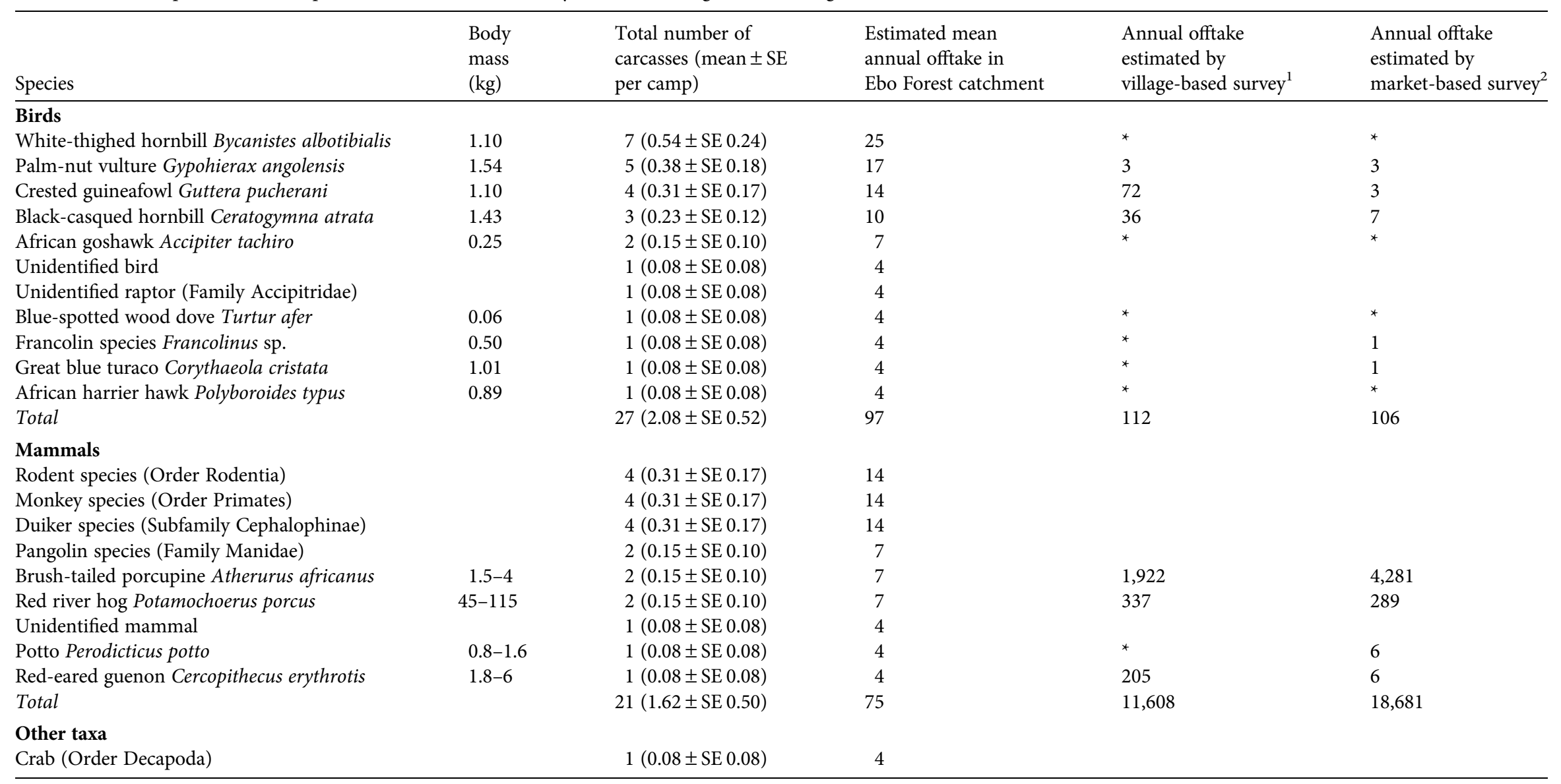

${ }^{1}$ Estimated from data presented in Willcox \& Nambu (2007). Values given for total extrapolated harvest over the entire survey period (34 months) were used to calculate annual offtake per $\mathrm{km}^{2}$ of the study area $\left(750 \mathrm{~km}^{2}\right)$ and extrapolated to our estimated catchment.

${ }^{2}$ Estimated from data presented in Fa et al. (2006). Values given for total estimated annual extraction in urban and rural markets were used to calculate offtake per km ${ }^{2}$ of the study area (35,0oo km²) and extrapolated to our estimated catchment.

*Species' range extends into the study area (Borrow \& Demey, 2004) but no carcasses were recorded. 
bird composition, or levels of bird hunting pressure may have increased in the intervening period (more than a decade) between the studies.

We believe that geographical differences are unlikely to be significant because bushmeat from the Ebo Forest is sold in several of the markets surveyed by Fa et al. (2006; E. Abwe, pers. comm.) and all of the birds identified here are found throughout the Cross-Sanaga region, which encompasses all three study areas. Furthermore, many hunters from across Cameroon have migrated to the Ebo Forest in recent decades (E. Abwe, pers. comm.) and Mamba village was founded by immigrant hunters in the 1970 (DowsettLemaire \& Dowsett, 2001), suggesting that bird hunting is not a cultural tradition exclusive to the Ebo Forest. We cannot categorically rule out the possibility that bird hunting has increased in the past decade, perhaps as a result of the depletion of other more commercially valuable species or the increased availability of shotguns, making it easier to kill canopy-living birds. However, the Ebo Forest retains relatively healthy populations of threatened mammals such as the drill (Morgan et al., 2013), and shotguns were the most frequently used hunting method in the BanyangMbo Wildlife Sanctuary during 1999-2002 (Willcox \& $\mathrm{Nambu}, 2007$ ), suggesting that there may be an alternative explanation.

We propose that the differences between the three studies are likely to be related to the commercial demand for species, with hunters consuming species for which there is little demand and selling more profitable species, such as African grey parrot and crested guineafowl, in villages and markets. This would explain why so few mammal remains were recorded in hunting camps as these generally have high commercial value and are traded in significant numbers in urban and rural markets (Fa et al., 2006; Willcox \& Nambu, 2007; Macdonald et al., 2011). However, we were unable to confirm this from our results as we did not record the number of birds traded in the region during the study period, or observe hunters consuming carcasses. We therefore recommend that future studies record simultaneously the number of kills reported by hunters and their financial value, and use direct methods to quantify bushmeat discarded in hunting camps and traded in markets. This would clarify whether the high level of bird hunting recorded was related to hunters consuming low-value species in camps, a temporal change in prey preferences, previous inaccurate reporting of harvest by hunters, or geographical variation between comparative studies.

The positive relationship between body mass and the number of bird carcasses recorded here has important implications for the conservation of large birds, such as hornbills and raptors, in the forests of Central Africa. Many hornbills are thought to be vulnerable to hunting pressure because of their low reproductive rates (Trail, 2007). For example, populations of the yellow-casqued hornbill
Ceratogymna elata (Vulnerable; IUCN, 2013) have experienced significant declines and range contractions in recent decades, which have been attributed partly to hunting pressure (BirdLife International, 2012). Results suggest that other forest hornbills, such as the range-restricted whitethighed hornbill, may be facing similar pressures. Hornbill population declines may also have important, broader implications for ecosystem function, as frugivorous species play an important role in seed dispersal and maintenance of forest structure (Brodie et al., 2009; Poulsen et al., 2013). Therefore, excessive hunting of these species should be cause for concern and we recommend that further investigations are made into potential hornbill declines in West and Central Africa.

Raptors, especially large, long-lived species that exhibit low fecundity, are likely to be similarly vulnerable to increased mortality caused by hunting (Owens \& Bennett, 2000; Krüger \& Radford, 2008). Studies of Egyptian vultures Neophron percnopterus, for example, have shown that low levels of mortality caused by anthropogenic activity can have a significant negative effect on populations (Carrete et al., 2009). The raptor detected most commonly among remains, the palm-nut vulture, is broadly similar to the Egyptian vulture in terms of body size and life history and is found throughout West and Central Africa where the oil palm Elaeis guineensis is sufficiently common (FergusonLees \& Christie, 2001). Palm-nut vultures have also been recorded in several previous bushmeat surveys carried out in Cameroon and elsewhere (Fa \& García Yuste, 2001; Fa et al., 2006; Willcox \& Nambu, 2007) and have traditionally been attributed a sweet-meat taste by hunters (e.g. Ghana; Lowe, 1937). Our results suggest that populations of this potentially threatened species may be experiencing unsustainable levels of hunting pressure.

Contrary to our expectations we recorded no crowned eagle carcasses during the study, although these large eagles are known to be consumed by hunters in the Ebo Forest (Whytock \& Morgan, 2010). Apart from direct persecution, crowned eagles are likely to occur at relatively low densities in hunted areas because of their high nutritional needs and preference for commercial bushmeat species (Struhsaker \& Leakey, 1990; Shultz \& Noë, 2002; cf. leopards: Henschel et al., 2011). The species' only known congener, Stephanoaetus mahery, became extinct in Madagascar c.1,100 years ago, probably as a result of anthropogenic pressures although it is not known if hunting was a contributory factor (Goodman, 1994). We suspect that crowned eagles may be among the birds most vulnerable to bushmeat hunting in the region, and further studies are needed to examine the potential effects of the direct and indirect threats posed by bushmeat hunting on populations of these and other large raptors.

In the wider region a number of studies on bushmeat harvest rates have attempted to account for the quantity of 
animals consumed by hunters in camps but indirect methods may have resulted in underreporting or species misidentification. Birds such as the Congo peacock Afropavo congensis (Vulnerable; IUCN, 2013), African fish-eagle Haliaeetus vocifer, crowned eagle and various hornbills, guineafowl, turacos and others have been reported from hunting camps in the Democratic Republic of Congo and Equatorial Guinea (T. Hart \& J. Hart, pers. comm; Fa \& García Yuste, 2001; Kümpel, 2006). Historical evidence suggests that birds such as raptors have always been targeted by hunters to some degree (Lindblom, 1938). We therefore believe that our results are representative of the wider region, particularly where shotguns are widely used, and although market surveys and indirect surveys of hunter offtake are essential tools for quantifying bushmeat harvests, these methods may have underestimated hunting pressure for some vulnerable, large-bodied birds in West and Central Africa.

\section{Acknowledgements}

We are grateful to the Ministry of Forestry and Wildlife and the Ministry of Scientific Research and Innovation for permission to conduct this research. We thank field assistant Zacharie Bekokon for his determined fieldwork; the people of Locndeng and Mamba villages for their technical support and permission to carry out the research; the Ebo Forest Research Project staff for significant logistical and managerial support; and the Offield Family Foundation, the U.S. Fish and Wildlife Service's Great Apes Conservation Fund, the Arcus Foundation, and the Margot Marsh Biodiversity Foundation for funding. The project would not have been possible without additional financial support from The Peregrine Fund, British Ecological Society, Leslie Brown Memorial Award (Raptor Research Foundation) and ACE Surveyors Ltd. Additional thanks are due to Alain Reygel for his assistance identifying remains, and to two anonymous reviewers for their valuable comments.

\section{References}

Abernethy, K.A., Coad, L., Taylor, G., Lee, M.E. \& Maisels, F. (2013) Extent and ecological consequences of hunting in Central African rainforests in the twenty-first century. Philosophical Transactions of the Royal Society B: Biological Sciences, 368, 20120303.

Allebone-Webb, S.M., Kümpel, N.F., Rist, J., Cowlishaw, G., Rowcliffe, J.M. \& Milner-Gulland, E.J. (2011) Use of market data to assess bushmeat hunting sustainability in Equatorial Guinea. Conservation Biology, 25, 597-606.

Bennett, E.L., Eves, H.E., Robinson, J.G. \& Wilkie, D.S. (2002) Why is eating bushmeat a biodiversity crisis? Conservation Biology: In Practice, 3, 28-29.

Bennett, E.L., Nyaoi, A.J. \& Sompud, J. (1997) Hornbills Buceros spp. and culture in northern Borneo: can they continue to co-exist? Biological Conservation, 82, 41-46.
Birdife International (2012) Ceratogymna elata. In IUCN Red List of Threatened Species v. 2012.1. Http://www.iucnredlist.org [accessed October 2012].

Borrow, N. \& Demey, R. (2004) Field Guide to the Birds of Western Africa. Christopher Helm Publishers, London, UK.

Brodie, J.F., Helmy, O.E., Brockelman, W.Y. \& Maron, J.L. (2009) Bushmeat poaching reduces the seed dispersal and population growth rate of a mammal-dispersed tree. Ecological Applications, $19,854-863$.

Carrete, M., Sánchez-Zapata, J.A., Benítez, J.R., Lobón, M. \& DONÁZAR, J.A. (2009) Large scale risk-assessment of wind-farms on population viability of a globally endangered long-lived raptor. Biological Conservation, 142, 2954-2961.

Chirio, L. \& LeBreton, M. (2007) Atlas des Reptiles du Cameroun. Muséum National d'Histoire Naturelle, Brunoy, France.

Djeukam, R. (2012) The Wildlife Law as a Tool for Protecting Threatened Species in Cameroon. Ministry of Forestry and Wildlife, Yaoundé, Cameroon.

Dowsett-Lemaire, F. \& Dowsett, R. (2001) First Survey of the Birds and Mammals of the Yabassi Area, South-Western Cameroon. Unpublished report. WWF, Yaoundé, Cameroon.

East, T., Kümpel, N.F., Milner-Gulland, E.J. \& Rowcliffe, J.M. (2005) Determinants of urban bushmeat consumption in Rio Muni, Equatorial Guinea. Biological Conservation, 126, 206-215.

Fa, J.E., Currie, D. \& Meeuwig, J. (2003) Bushmeat and food security in the Congo Basin: linkages between wildlife and people's future. Environmental Conservation, 30, 71-78.

FA, J.E. \& García Yuste, J.E. (2001) Commercial bushmeat hunting in the Monte Mitra forests, Equatorial Guinea: extent and impact. Animal Biodiversity and Conservation, 24, $31-52$.

Fa, J.E., Johnson, P.J., Dupain, J., Lapuente, J., Köster, P. \& Macdonald, D.W. (2004) Sampling effort and dynamics of bushmeat markets. Animal Conservation, 7, 409-416.

Fa, J.E., Seymoura, S., Dupain, J., Aminc, R., Albrechtsend, L. \& Macdonald, D. (2006) Getting to grips with the magnitude of exploitation: bushmeat in the Cross-Sanaga rivers region, Nigeria and Cameroon. Biological Conservation, 129, 497-510.

Ferguson-Lees, J. \& Christie, D.A. (2001) Raptors of the World. A\&C Black, London, UK.

Fotso, R., Dowsett-Lemaire, F., Dowsett, R.J., Cameroon Ornithological Club, Scholte, P., Languy, M. \& Bowden, C. (2001) Cameroon. In Important Bird Areas in Africa and Associated Islands: Priority Sites for Conservation (eds L.D.C. Fishpool \& M.I. Evans), pp. 133-160. BirdLife International, Cambridge, UK.

Fry, C.H., Keith, S. \& Urban, E.K. (1988) The Birds of Africa, Vol. 3. Academic Press, London, UK.

Goodman, S.M. (1994) Description of a new species of subfossil eagle from Madagascar-Stephanoaetus (Aves, Falconiformes) from the deposits of Ampasambazimba. Proceedings of the Biological Society of Washington, 107, 421-428.

Henschel, P., Hunter, L.T.B., Coad, L., Abernethy, K.A. \& Múhlenberg, M. (2011) Leopard prey choice in the Congo Basin rainforest suggests exploitative competition with human bushmeat hunters. Journal of Zoology, 285, 11-20.

IUCN (2013) IUCN Red List of Threatened Species v. 2013.1. Http:// www.iucnredlist.org [accessed July 2013].

Jones, J.P., Andriamarovololona, M.M., Hockley, N., Gibbons, J.M. \& Milner-Gulland, E.J. (2008) Testing the use of interviews as a tool for monitoring trends in the harvesting of wild species. Journal of Applied Ecology, 45, 1205-1212. 
Kingdon, J. (1997) The Kingdon Field Guide to African Mammals. Academic Press, London, UK.

Krúger, O. \& Radford, A.N. (2008) Doomed to die? Predicting extinction risk in the true hawks Accipitridae. Animal Conservation, 11, 83-91.

KÜMPEL, N.F. (2006) Incentives for sustainable hunting of bushmeat in Rio Muni, Equatorial Guinea. PhD thesis. Imperial College, London, UK.

Laga (Last Great Ape Organization) (2012) Annual Report January-December 2012. Unpublished report. LAGA, Yaoundé, Cameroon.

Lindilom, G. (1938) An ethnographical proof of the honey buzzard's migrations to Cameroon. 1. Ethnos, 3, 4-7.

Lowe, W.P. (1937) Report on the Lowe-Waldron expeditions to the Ashanti forests and Northern Territories of the Gold Coast. Ibis, 79, 345-368, 635-662, 830-864.

Macdonald, D.W., Johnson, P.J., Albrechsten, L., Dutton, A., Seymour, S., Dupain, J. et al. (2011) Association of body mass with price of bushmeat in Nigeria and Cameroon. Conservation Biology, $25,1220-1228$

McConkey, K.R. \& Chivers, D.J. (2004) Low mammal and hornbill abundance in the forests of Barito Ulu, Central Kalimantan, Indonesia. Oryx, 38, 439-447.

Milner-Gulland, E.J., Bennett, E.L. \& the SCB 2002 Annual Meeting Wild Meat Group (2003) Wild meat: the bigger picture. Trends in Ecology \& Evolution, 18, 351-357.

Morgan, B.J. (2008) The gorillas of the Ebo Forest. Gorilla Journal, $36,14-16$.

Morgan B.J. (ed.) (2011) Regional Action Plan for the Conservation of the Nigeria-Cameroon Chimpanzee (Pan troglodytes ellioti). IUCN/SSC Primate Specialist Group and Zoological Society of San Diego, San Diego, USA.

Morgan, B.J., Abwe, E.E., Dixson, A.F. \& Astaras, C. (2013) The distribution, status, and conservation outlook of the drill (Mandrillus leucophaeus) in Cameroon. International Journal of Primatology, 34, 281-302.

Oates, J.F., Bergl, R.A. \& Linder, J.M. (2004) Africa's Gulf of Guinea Forests: Biodiversity Patterns and Conservation Priorities. Conservation International, Washington, DC, USA.

Owens, I.P.F. \& Bennett, P.M. (2000) Ecological basis of extinction risk in birds: habitat loss versus human persecution and introduced predators. Proceedings of the National Academy of Sciences of the United States of America, 97, 12144-12148.
Poulsen, J.R., Clark, C.J. \& Palmer, T.M. (2013) Ecological erosion of an Afrotropical forest and potential consequences for tree recruitment and forest biomass. Biological Conservation, 163, 122-130.

Rist, J., Milner-Gulland, E.J., Cowlishaw, G. \& Rowcliffe, M. (2010) Hunter reporting of catch per unit effort as a monitoring tool in a bushmeat-harvesting system. Conservation Biology, 24, 489-499.

Shultz, S. \& NoË, R. (2002) The consequences of crowned eagle central-place foraging on predation risk in monkeys. Proceedings of the Royal Society B: Biological Sciences, 269, 1797-1802.

Struhsaker, T.T. \& Leakey, M. (1990) Prey selectivity by crowned hawk-eagles on monkeys in the Kibale Forest, Uganda. Behavioral Ecology and Sociobiology, 26, 435-443.

Trail, P.W. (2007) African hornbills: keystone species threatened by habitat loss, hunting and international trade. Ostrich, 78, 609-613.

Urban, E., Fry, C. \& Keith, S. (eds) (1982) The Birds of Africa, Vol. 2. Academic Press, London, UK.

Whyтоск, R.C. \& Morgan, B.J. (2010) The commercial bushmeat trade potentially threatens raptor populations in the Ebo forest, Cameroon. GABAR, 1, 1-7.

Wilkie, D.S. \& Carpenter, J.F. (1999) Bushmeat hunting in the Congo Basin: an assessment of impacts and options for mitigation. Biodiversity and Conservation, 8, 927-955.

Willcox, A.S. \& NAmBU, D.M. (2007) Wildlife hunting practices and bushmeat dynamics of the Banyangi and Mbo people of Southwestern Cameroon. Biological Conservation, $134,251-261$.

\section{Biographical sketches}

Roвin Whyтоск's research interests include investigating the decline of Afro-Palaearctic migrants and the conservation ecology of birds in the Lower and Upper Guinean forests. RALPH BUIJ studies the ecology and conservation of avian and mammalian populations in the tropics of Central/West Africa and Indonesia, focusing on the effects of human infrastructure, land-use change, hunting, and protected area management. MUNIR Virani has studied the ecology and conservation of raptors in East Africa. His current research focuses on vulture conservation in East Africa and South Asia. BEthan MORGAN is has lived and worked in central Africa, promoting the conservation and research of a range of threatened species. 